\title{
Virtue and Prejudice: Giving and Taking Reasons
}

\author{
Noell Birondo*
}

\begin{abstract}
The most long-standing criticism of virtue ethics in its traditional, eudaimonistic variety centers on its apparently foundational appeal to nature in order to provide a source of normativity. This paper argues that a failure to appreciate both the giving and taking of reasons in sustaining an ethical outlook can distort a proper understanding of the available options for this traditional version of virtue ethics. To insist only on giving reasons, without also taking (maybe even considering) the reasons provided by others, displays a sadly illiberal form of prejudice. The paper finds and criticizes such a distortion in Jesse Prinz's recent discussion of the "Normativity Challenge" to Aristotelian virtue ethics, thus highlighting a common tendency that we can helpfully move beyond.
\end{abstract}

We might ask, for example: how could Socrates talk philosophy and set the discussion in order without a body? But if he could not, and if the interlocutors believe that the ability to participate in the give and take of dialectic is essential, as part of being human, to the Socrates they know... then we must concede that there is some incoherence in the wish that Socrates go off from his body to the happy life of the blessed.

-Martha Nussbaum (1995, 93)

\section{INTRODUCTION}

The most long-standing criticism of virtue ethics, at least in its traditional, eudaimonistic variety, centers on its apparently foundational appeal to nature in order to provide a source of normativity: its attempt to validate, by appealing to the nature of human beings, that certain traits of character amount to exemplary, excellent, or virtuous traits of character. But many defenders of virtue ethics have insisted that a naturalistic validation of the virtues might proceed in two quite different ways. One side of the distinction is sometimes cast in this Neurathian image: that when we extol certain traits of character as virtues of character, and when we give our reasons for doing so, we are like sailors rebuilding our ship on the open sea. Any particular conception of eudaimonia - the vessel by which one might navigate the ethical waters-remains

* Wichita State University. E-mail: Noell.Birondo@wichita.edu

(C) The Author 2016. Published by Oxford University Press on behalf of The Hegeler Institute.

All rights reserved. For permissions, please e-mail: journals.permissions@oup.com 
always open to revision, an acknowledgement of its fallibility. That approach contrasts with a more ambitious validation of the ethical virtues, one that proceeds from naturalistic materials that lie, already in dry dock, external to the ship. A traditional candidate here is Aristotle's alleged appeal to an 'absolute' conception of nature, replete with its metaphysical biology. ${ }^{1}$ With this distinction in hand, virtue ethicists can claim that the long-standing criticism applies only to very ambitious 'external' appeals to nature.

A less ambitious validation of the ethical virtues-one that appeals, selfconsciously, to a conception of human nature that is, of course, open to disputecan still seem well worth our philosophical attention. Indeed, the Neurathian image looks like an invocation of mere modesty: in this context it amounts to the familiar liberal idea that 'our' conception of the best way to live, something that is of course the product of culture, might be in various ways mistaken. Ethically sound practice involves, according to this modest outlook, not only the giving of reasons for our ethical conceptions, but also the taking of such reasons from those whose conceptions differ from our own. This idea of the 'giving and taking of reasons' is something that I mean in a completely mundane sense-it is the mundane sense employed by Martha Nussbaum when she appeals, without explication, to the 'give and take' of philosophical dialectic, in the quotation with which this paper begins. Such give and take implies neither-absurdly-accepting all of the reasons which one is offered no matter how irrational or outlandish, nor-stubbornly-merely claiming that one will consider the reasons which one has been offered. The claim that "I'll consider it" is often meant to indicate that genuine discussion has come to an end. Such a claim is often meant, indeed, as a shut down. Hence the phrase 'taking reasons' is more helpful in this context than the phrase 'considering reasons', since 'taking reasons' is helpfully ambiguous between someone's genuinely and open-mindedly taking into consideration the reasons that have been offered by others, and actually taking (or accepting or embracing) those very reasons as her own. My claim in this paper is that a failure to appreciate both the giving and the taking of reasons in sustaining an ethical outlook-a failure to appreciate the kind of understanding and transformation that can be effected by a rational exchange of practical considerations between different ethical communities—can distort one's understanding of what an 'internal' validation of the virtues would ultimately amount to. To insist only on giving reasons, without also taking (maybe even considering) the reasons provided by others, displays a sadly illiberal form of prejudice.

In order to illustrate the distortion just mentioned, I will consider its appearance in one recent discussion of virtue ethics; but I hope that the considerations advanced in what follows make it clear that such a distortion is hardly confined to the discussion I single out for attention. The distortion I have in mind makes a prominent appearance in Jesse Prinz's recent criticisms of virtue ethics (2009) from the perspective of what he calls the "Normativity Challenge." An examination of Prinz's views regarding this challenge will help illuminate the importance of both giving and taking reasons in sustaining an ethical outlook; but the discussion of Prinz's views ( $\$ \$ 2-3)$ will also help bring into focus what I have thus far referred to only opaquely as the long-standing criticism to virtue ethics. 


\section{PRINZ ON WELL-BEING AND ITS RELATION TO EUDAIMONIA}

The challenge that Prinz sets for virtue ethics can itself be brought into focus by first specifying more precisely the difference between an 'external' and 'internal' validation of the virtues. An external validation of the virtues of character is an attempt to demonstrate that possession of the virtues of character is necessary in order to secure some good, or to avoid some harm, where the good in question, or the harm, is recognizable as such independently of the particular evaluative outlook provided by possession of the virtues themselves. The validation will thus rely on resources that are 'external' to the particular evaluative outlook to be validated. By contrast, an internal validation of the ethical virtues would be one according to which the good unattainable without the virtues, or the harm unavoidable without them, is only recognizable as such from within the evaluative outlook provided by possession of the ethical virtues themselves, although this evaluative outlook might also be shared by people who (like most of us) never manage to proceed further than Aristotelian continence. ${ }^{2}$

The aim of Prinz's Normativity Challenge, as I understand it, ${ }^{3}$ is to press the following thought: that neither an external validation nor an internal validation of the ethical virtues is at all likely to succeed. This can be demonstrated, he thinks, by appealing to empirical studies from cultural psychology that emphasize the differing conceptions of 'well-being' across cultures. If neither type of validation can succeed, then the alleged "normativity of the virtues" will remain unexplained. According to Prinz this constitutes a more serious challenge to virtue ethics than the much-touted 'Situationist Challenge.' This is a challenge that Prinz thinks can be adequately answered, on behalf of virtue ethicists, by appealing to the same types of studies from cultural psychology. ${ }^{4}$ In this paper my concern will be with what Prinz says about the Normativity Challenge to virtue ethics.

Before turning to that, some preliminaries are in order. Specifically, something needs to be said about Prinz's understanding of the appeal, within Aristotelian versions of virtue ethics, to the notion of eudaimonia or "flourishing." For it immediately becomes unclear which proponents of virtue ethics Prinz has in mind in his discussion. The question that Prinz puts to virtue ethics is this $(2009,132)$ : "What is the source of this obligation," he asks, the one that says that we "should cultivate the virtues"? Having asked this question, Prinz goes on to characterize, on the subsequent page, what he apparently takes to be some genuinely Aristotelian answers to it. ${ }^{5} \mathrm{He}$ insists that, whereas theists might see the normativity of the virtues in terms of divine command, Aristotelians "tend to go another route." More specifically, they argue "that morality derives from natural teleology." By appealing to such natural teleology, the proponents of an Aristotelian virtue ethics maintain that, "The normativity of the virtues derives from the fact that they are the end to which our nature directs us, and thus constitute human flourishing."

However, flourishing is not at all constituted, on an Aristotelian view, by any state or disposition of character, not even virtue. Aristotle's own view, which has hardly been rejected by prominent defenders of virtue ethics, ${ }^{6}$ maintains that eudaimonia is, over a complete life, rational activity in accordance with virtue (NE 1098a16-18). Thus on Aristotle's view, the flourishing life is a life constituted by a certain type of activity, not by a state or disposition of a person's psychology. No state or disposition 
of a person's psychology, not even virtue, could possibly constitute flourishing as Aristotle understands it. This is because the possession of that state or disposition, whatever it is, remains consistent with a completely inactive life, a life that involves no virtuous activity (NE 1098b30-1099a5; cf. 1102b5-8). Hence whatever traits of character the ethical virtues turn out to be, activity in accordance with those traits, over a complete life, just is what flourishing, according to Aristotle, ultimately is.

A life of virtuous activity is also, of course, a life of affect: it is a life of both doing and feeling, a life that good people find enjoyable. Perhaps it is on the basis of such Aristotelian thoughts that Prinz says that flourishing is "widely presumed to involve certain affective states." He then claims (1) that flourishing is "related to" well-being and (2) that well-being is "an affective construct," a "subjective state." Prinz goes on to clarify that for Aristotelians the virtues are good "not simply because they make us feel good, but because they make us feel good in a way that is indicative or constitutive of having fulfilled our natural ends as a species." The view that Prinz has in mind maintains that, "Well-being confers normative status not because of its hedonic qualities, but because of its teleological status." Thus, according to the 'Aristotelian' versions of virtue ethics that Prinz has in mind, Aristotelian flourishing (eudaimonia) drops out of the picture altogether, except insofar as it 'relates to' subjective conceptions of well-being. One might therefore characterize the target of Prinz's arguments here as 'Aristotelianism without eudaimonia." What is the new empirical challenge that Prinz takes to be problematic for virtue ethics so understood?

\section{THE LONG-STANDING CRITICISM OF VIRTUE ETHICS}

The Normativity Challenge seems to press the idea that neither an external validation nor an internal validation of the ethical virtues is at all likely to succeed. Consider what Prinz says about each of these approaches for validating certain traits of character as genuine virtues of character.

An internal, Neurathian validation of the virtues would be, as I said above, an attempt to demonstrate that there is some good, say, that is unattainable without possession of the ethical virtues, where the good in question is recognizable as such only from within the evaluative outlook provided by possession of the ethical virtues themselves. However, as Prinz points out in considering this type of proposal, showing that a certain tendency is natural obviously falls well short of showing that it is good, since whole cultures might have natural tendencies toward violence and warfare. Perhaps we can draw a distinction, though, between natural tendencies that are "noble" and those that are not. But Prinz insists that, "It is hard to do this without circularity." This is because one "cannot define noble natural tendencies as those that accord with virtue, and then argue that virtues derive normativity from their status as natural" (2009, 133-34). That is Prinz's argument against an internal validation of the ethical virtues. I will return to it briefly below in $\$ 5$, after considering the alternative, external approach.

An external validation of the ethical virtues is an attempt to demonstrate that there is some good, say, that is recognizable as such independently of the evaluative outlook provided by the ethical virtues and that is clearly unattainable without possession of those virtues. In order to articulate such a validation, virtue ethicists might want, Prinz says, "to beef up their notion of well-being" $(2009,134)$. The strategy would be this: "If a 
substantive account of well-being can be offered that makes no reference to virtue, then we can define the virtues as the natural behaviors that promote well-being without any circularity" $(2009,134)$. Here one might compare Prinz's formulation of a substantive account of well-being to Thomas Hurka's formulation (unacknowledged in Prinz's paper) of the same idea. As Hurka puts this idea: "A substantive conception equates flourishing with some determinate state $F$ of people or their lives, where both the nature and the goodness of $F$ are defined independently of the virtues" (Hurka 2001, 235; quoted in Annas 2008). ${ }^{8}$

Prinz, however, thinks that there is an obvious problem with this substantive strategy. This is the fact that "there are well-documented cultural differences in which factors matter" for well-being $(2009,134)$. After noting some of the empirical studies documenting these cultural differences (studies which I have no reason to question for my purposes here), Prinz sums up this line of thinking as follows:

This variation has serious implications for virtue ethics. Virtue ethicists have traditionally assumed that there is a universal set of virtues; indeed many virtue ethicists try to list them. And, they assume that these virtues are universal precisely because they are all part of a universal human nature. But that supposition is untenable. What leads to fulfillment in life is neither universal nor entirely natural. Culture can shape our conception of the good life. $(2009,134)$

In this passage, the word "fulfillment" presumably refers to well-being, achieved according to a specific conception of it. Hence Prinz's thought can be put like this: subjective conceptions of well-being, resulting as they do from the influence of culture, are neither universal nor entirely natural. Thus the prospects for 'deriving' a universal list of the virtues from an account of well-being, construed in these terms, seems especially dim. An external validation of a set of universal virtues - a validation that takes a subjective conception of well-being to be the good that is unattainable without the virtues-is not, as Prinz sees it, very likely to succeed. He nevertheless considers what he takes to be the available options, at this point, for defenders of an Aristotelian version of virtue ethics.

The options constitute, he says, an unattractive dilemma. On the first horn of the dilemma, virtue ethicists might defend the idea that-in spite of the wide cultural variation in subjective conceptions of well-being - there is, nevertheless, a universal set of ethical virtues that promotes "all forms of well-being" $(2009,136)$. This is what we might call the off-brand conception of virtue. Prinz rightly passes over this idea without comment.

On the second horn of the dilemma, virtue ethicists might maintain that some conceptions of well-being are, after all, better than others. But Prinz says that "such an argument would inevitably hinge on one of two mistakes" $(2009,136)$. The first mistake is this: In assessing alternative conceptions of well-being "from within" (or better: from) our own evaluative outlook, we would "inevitably," Prinz says, "impose our own conception of well-being on others, when determining which is best" $(2009,136)$. This would amount to an objectionable form of cultural chauvinism (I will return to this point below in $\$ 4$.) The second mistake would be to go further external: to argue from an allegedly neutral, cultural-free standpoint that some conceptions of well-being 
emerge as more natural, and therefore as 'better', than others. Prinz's passionate rejection of any such appeal is worth quoting at length, since it encapsulates the 'long-standing' criticism of virtue ethics that I referenced at the outset. Prinz points out that this external strategy "assumes a conception of the human species that is profoundly false." He elaborates:

We are a cultural species, and it is part of our nature that our values should be forged in the context of human interactions. To the extent that those interactions engender different conceptions of well-being, as the empirical literature shows, we cannot pretend that there is some pre-social, purely natural conception. That is the myth of the noble savage. Indeed, if we could find such a pre-cultural conception, it would have scant normative force, for conceptions of well-being that did not emerge through cultural processes would hardly be applicable or conducive to thriving once we find ourselves situated in a cultural context. Faith in a universal form of well-being teeters between cultural chauvinism and a form of naturalism rivaling Spencer's in its naiveté and vulgarity. (2009, 136)

The main thing to say, however, about the position targeted by this long-standing criticism is that many quite prominent defenders of a eudaimonistic version of virtue ethics have explicitly rejected it. ${ }^{9}$ Certainly as an interpretation of Aristotle, the view has been fairly well repudiated. Julia Annas, for instance, writing more than twenty years prior to Prinz's paper, insists quite generally that:

The Greeks did not support their various claims about happiness and virtue by an appeal to teleology, nor to a fixed and determinate pattern of human nature which would impose on the recalcitrant agent a rigid and specific set of aims and mode of life. The appeal was rather to what we would call the best available moral psychology-something much more general, and disputable. $(1988,165)^{10}$

Hence the long-standing criticism of virtue ethics, as Prinz seems not to realize, is well off the mark. The appeal to an allegedly neutral, teleological conception of nature-as many contemporary virtue ethicists have long recognized-ought to be abandoned. Nevertheless, if a certain culture stands equipped with a subjective conception of wellbeing, one that its members consider to be better than the alternative conceptions, won't this attitude of superiority "inevitably" lead, as Prinz says, to imposing their conception of well-being on others? Won't insisting on the superiority of 'our' conception of well-being amount to a form of cultural chauvinism? The answers to these questions will help illustrate the distortion that I hope to bring out: the culprit is failing to appreciate the importance of both giving and taking reasons in sustaining an ethical outlook. In order to illustrate the phenomenon I have in mind, in the next section I consider, at some length, a case that Prinz deploys from cultural psychology. It involves two contrasting conceptions of well-being from two different cultural communities. What can we learn from such a case? 


\section{AGRARIAN TOLERATION AND IMPERIALISM}

Suppose that the well-being of a certain agrarian community depends upon various forms of cooperation in the sharing of agricultural resources (cf. Prinz 2009, 129). The members of this community therefore tend to value cooperativeness in the sharing of such resources. Moreover, they insist that their own cooperative conception of well-being is better than the one embraced by the herders in the hills. The herders work in isolation and are, as a result, more prone to violence, for instance in defense of their flocks. Do the agrarians display a form of cultural chauvinism, insofar as they consider their own cooperative conception of well-being to be better than the violent alternative? Are they bound "inevitably" to impose their conception of well-being on others? There are many things to say in response to these questions, the answers to which, as we saw above, Prinz takes to be obviously affirmative. Here I will mention three points that suggest otherwise.

First, if the agrarians can prosper without interference from the herders, then the agrarians may not be, and perhaps should not be, especially concerned about the herders' tendencies toward violence. If a life that is overly prone to violence contributes to the different type of well-being enjoyed by the herders-given that the hills are so dangerous-then so much the better for the herders, and for their flocks. The agrarians need not be, and perhaps should not be, in any way involved. They need not even understand the way of life in the hills in order to adopt this attitude of toleration. ${ }^{11}$ In any case, even if they did understand it, what reasons could the agrarians give (left as the herders are to fend for themselves) to embody the 'agrarian' virtues-e.g., the virtue of trust? The agrarians could of course insist that the virtue of trust contributes, as they themselves see it, to the well-being of agrarians. But they cannot plausibly insist that such a trait contributes to the well-being of herders: If the hills are especially dangerous, then such a claim is simply false. (Recall that we have already dismissed the implausible off-brand conception of virtue.) Hence the question of imposing a specific conception of well-being on others need not arise. Nor need the agrarian attitude of tolerance amount to a form of cultural chauvinism; the attitude that I have described can be maintained in full awareness that the herders look down in condescension on the agrarian way of life. This all remains perfectly consistent with the agrarians' insistence that their own conception of well-being is much better than the alternative conception, the one that incorporates habitual violence.

Of course the situation becomes rather different-this is the second point-if the herders descend from the hills. It may be that the herders threaten, not the agrarian way of life, but at least the lives of certain agrarians. In this case there may be no alternative to threatening sanctions against the herders: If the case becomes desperate, this will become the threat of violence, or, at the limit, simply violence. But in this case the imposition of a peaceful coexistence, by means of threatened external sanctions, looks like a justifiable imposition. (I will come back to "looks" in the next paragraph.) The situation becomes different again, of course, if the herders threaten, or even seem to threaten, the agrarian way of life. In that case the well-being of the agrarians becomes, or seems to become, compromised. The question that arises then-whether defending one's way of life 
justifies the threat of sanction, and even violence, in the face of a real or perceived threat from some new cultural element-is obviously a question that is too large to address adequately here. But what I do want to insist upon should be predictable. In a society comprising members from both the agrarian and the herder communities-i.e., in a multicultural society-only a regrettably illiberal form of prejudice can seem to justify giving reasons for one's own conception of well-being while refusing to take into consideration the reasons provided by others for their differing conceptions. Charles Taylor remarks in a similar context on what he takes to be a "general truth" about life in a society that is both multicultural and democratic; this general truth is that "contemporary democracies, as they progressively diversify, will have to undergo redefinitions of their historical identities, which may be far-reaching and painful" (Taylor 2011, 317). What this observation highlights is that, although the agrarians may initially consider their own conception of well-being to be better than that of the herders-and although there may be nothing objectionable about that-the agrarians still cannot justifiably close their minds to the reasons offered by the herders for their different conception of well-being, violence-prone though it may be. Presumably there are reasons (which, for all we know, may be excellent reasons) for their traditional security concerns; and so presumably there are also reasons for their tendencies toward violence. Perhaps it will be the agrarians who come to realize-after taking (or accepting or embracing) such security reasons from the herder communitythat their own agrarian conception of well-being is overly pacific or naive, or anyway too prone to a blind and defenseless form of trust. ${ }^{12}$

These considerations lead us to a third and final point about imposing our conception of well-being on others. While I said that the threat of sanctions against the herders looks, in some cases, like a justifiable imposition, it is a good question whether any behavior can in fact be ethically justified here, given the restrictions on the type of 'external' validation under discussion. This is an attempt, recall, to 'derive' a universal set of virtues from a subjective conception of well-being "that makes no reference to virtue" (Prinz 2009, 134). In that case, though, if the agrarian conception of well-being is 'substantive' in Prinz's sense, in the sense of being articulable without making any reference to virtue, then the threat of sanctions can only apparently be justifiable in this pragmatic sense: because such activity promotes agrarian well-being. In that case, though, any action that genuinely promotes the well-being of the agrarians will turn out to be, in that pragmatic sense, justifiable. The problem here is not, as Prinz says, that since the agrarians consider their own conception of well-being to be better than that of the herders, this means that they will 'inevitably' impose their conception of well-being on others. Nor is the problem here, as I argued above, that the attitude of superiority amounts to a form of cultural chauvinism. The problem is rather that without the giving and the taking of reasons-without the rational exchange of practical considerations between the agrarian and herder communities - an insulated and culture-bound conception of well-being provides a recipe for justifiable cultural imperialism. This consequence, though, is not a problem for eudaimonistic versions of virtue ethics, but rather for Prinz's understanding of them. ${ }^{13}$ 


\section{CONCLUSION: GIVING AND TAKING REASONS}

The discussion so far would seem to leave an 'internal' validation of the ethical virtues as the remaining strategy for answering Prinz's Normativity Challenge. Such a validation, as I said, would be an attempt to demonstrate that possession of the ethical virtues is necessary in order to secure some good, or to prevent some harm, where the good in question, or the harm, is recognizable as such only from within the evaluative outlook provided by possession of the virtues themselves. Thus the good to be achieved by possession of the virtues will rather obviously not be characterizable without any (even implicit) reference to them. But the outlook in question can also be shared by people who, like most of us, never manage to proceed further than Aristotelian continence. And the possibility of shared overlap amongst differing ethical conceptions makes theoretical and ethical progress possible. An appreciation of the kind of giving and taking of reasons that I am advocating requires, as I suggested above, a kind of modesty that allows for an open-ended rational exchange with others, with those who hold different ethical conceptions than our own. And this modesty, when actually embodied, ought to mitigate familiar worries about circularity, ${ }^{14}$ or about the inevitability of imposing our conception of the good life on others. Moreover, this way of understanding an internal validation of the virtues, by insisting upon the giving and taking of reasons, seems anyway to be required by any version of eudaimonism that hopes to steer clear of the long-standing criticism of virtue ethics. $^{15}$

In order to effect ethical progress, those engaged in ethical reflection need to acknowledge the two reciprocal practices that invoke ethical reasons here-not only the practice of giving reasons for our ethical conceptions, but also the practice of taking the reasons of others into account, even though these others may embrace ethical conceptions that differ radically from our own. Thus perhaps the Neurathian imagery, at least for eudaimonistic versions of virtue ethics, might emerge as less than fully appropriate, since according to the strategy defended in this paper, the vessel in question-a specific conception of eudaimonia-would remain helpfully porous. Or perhaps this dual practice, of giving and taking reasons, needs to invoke a slightly different image: one that involves a fusion of ethical horizons. Regarding this different, Gadamerian image, Charles Taylor has observed that the slogan here might be: "no understanding the other without a changed understanding of self" $(2002,295)$. Hence the illiberal prejudice involved in my discussion might also be thought of as an implicit and unjustified rejection of, or at least a resistance to, the idea encapsulated in this slogan, of a changed understanding of our own ethical outlook, and also (one might add) of a changed understanding of ourselves. ${ }^{16}$

\section{NOTES}

1. The allusions here are to Bernard Williams (1985, ch. 3) and Alasdair MacIntyre (1984, ch. 12). For other influential advocates of this general reading of Aristotle, see the works cited in Nussbaum (1995, n. 2).

2. For this account of the distinction, and for discussion, see Birondo (2015). On the nonmatching overlap between the continent person's outlook and the virtuous person's outlook in specific cases, see McDowell (1979), especially $\$ 3$.

3. An interpretation of Prinz's argument here is somewhat hampered by the fact that, in the section of his paper devoted to explicating the 'Normativity Challenge' (sometimes also the 'Normative Challenge'), 
various views are attributed to Aristotle, and to contemporary 'Aristotelian virtue ethicists', without there being any citations to Aristotle, or to any contemporary Aristotelian virtue ethicists. A possible exception is Prinz's reference to Martha Nussbaum, in support of the claim that, in Prinz's words, "some cultures may find exposure to the natural environment more important than others" (Prinz 2009: see section 4, "Normativity: Another Empirical Challenge to Virtue Ethics"). Hence, Prinz's new empirical challenge to virtue ethics relies on what he apparently considers to be the a priori options for it.

4. However, even this much is unclear: Mark Alfano has issued some worries about whether Prinz's appeal to such studies, on behalf of virtue ethicists, actually does answer the situationist challenge. See Alfano (2013, 51-52).

5. The quotations from Prinz in this section of my paper will accordingly be from that page of Prinz's paper: $(2009,133)$.

6. See, for instance, McDowell (1980), Annas (1993), Nussbaum (1995), Hursthouse (1999).

7. Sebastian Purcell (2014) has argued, in response to this 'Normativity Challenge', that Prinz's understanding of Aristotelian eudaimonia relies on presuppositions "that are not supported by a careful reading of the Nicomachean Ethics.” My own response cannot quite muster Purcell's admirable charity.

8. In defense of virtue ethics, Julia Annas responds by insisting that, "Where success is defined independently of the virtues, it will always be hopeless to try to show that the virtues are a good way of achieving that" $(2008,214)$.

9. See, for instance, McDowell (1995), Hursthouse (1999), Annas (2008), Russell (2009). MacIntyre is a special case here, since he rejects the natural-teleological position targeted by the long-standing criticism (1984) but also again (1999) feels its attractions. But even on MacIntyre's later view, as Christopher Toner has recently stressed, some Neurathian considerations are at work. See Toner (2008, \$S5-6).

10. Regarding Aristotle in particular, Annas writes that, "Aristotle does not have a 'universal teleology', and the teleology he has is not a theory about human lives" $(1988,156)$. (Some of the material from this article, Annas [1988], was later incorporated, in an expanded form, in an even more prominent venue: Annas [1993, Part II, "Justification and the Appeal to Nature”]. See p. 136, n. 4.) Other prominent interpretations of Aristotle's ethics that would show the long-standing criticism to be quite off target include McDowell (1980) and, in exquisite detail, Nussbaum (1995).

11. These claims are not meant to deny that there can of course be cases in which humanitarian intervention is justified.

12. The point here is not to make an empirical prediction about the likelihood of convergence between initially differing conceptions of well-being, but rather to highlight its rational possibility.

13. Nor is it the case that Aristotelian versions of eudaimonism fall prey to the charge under discussion, of imposing a specific conception of the good life on others. Julia Annas provides some of the reasons why not. See Annas $(2008,217)$.

14. On the worry about circularity, consider a few especially prominent discussions that are not considered or acknowledged in Prinz's paper: Annas (1993), Nussbaum (1995), McDowell (1995). In dismissing the 'internal' strategies deployed in these discussions, it does not seem to me to be sufficient to remark, without any detailed consideration of the discussions themselves, that it is "hard to do this without circularity" (Prinz 2009, 133). Moreover, as I have understood the notion in this paper, the giving and the taking of reasons should mitigate worries from this direction: Even if one eventually arrives back at the same point from which one's rational reflection set off, there was no guarantee, in advance of such reflection, that this outcome would eventuate; and of course it may not eventuate. The image of circularity here is a bogeyman. (See also the subsequent note.)

15. Nevertheless, Christopher Toner has recently issued the following objection in defense of a broadly MacIntyrean-Thomistic picture of universal human nature: that the sort of naturalism defended by McDowell (e.g., in McDowell [1995]) "seems to give way to a lightly constrained moral relativism, in which morality is multiply, and variably, realized in a diverse assortment of cultures" (Toner 2008, 228). MacIntyre himself maintains quite differently that, "It has often been thought by Thomists ... that to acknowledge the historically conditioned character of philosophical—or for that matter scientific or historical-inquiry is to make a certain kind of relativism inescapable. And it was one of the several achievements of [Hans-Georg Gadamer's] Wahrheit und Methode to have shown that this is not so" (MacIntyre 2002, 158). For McDowell's response to the general charge of relativism, invoking both Gadamer and Donald Davidson, see McDowell (2002). Although I cannot develop this point here, a view like Toner's seems to me to display a version of the prejudice that $I$ have aimed to articulate in this paper; a fuller treatment would be required to show exactly how so. 
16. Earlier versions of this paper were presented at the Australian Catholic University, Melbourne, for the Reason and Virtues Conference in 2015, and also at Wichita State University. Thanks are due to the participants on each of these occasions and to the conference organizers; to the students in my History of Ethics (2015) and Contemporary Ethics (2014) courses; and to two anonymous referees for The Monist. Special thanks are due to my colleagues Robert Feleppa and David Soles for their extremely helpful written comments; to Lillian Dickerson, Avery Kolers, Kate Phelan, and Kai Spiekermann, for their much-needed encouragement; and to Robert Audi for his generosity and support.

\section{REFERENCES}

Alfano, Mark 2013. Character as Moral Fiction, New York: Cambridge University Press.

Altham, J.E.J. and Ross Harrison, eds. 1995. World, Mind, and Ethics: Essays on the Ethical Philosophy of Bernard Williams, Cambridge: Cambridge University Press.

Annas, Julia 1988. "Naturalism in Greek Ethics: Aristotle and After," Proceedings of the Boston Area

Colloquium in Ancient Philosophy 4: 149-71.

- 1993. The Morality of Happiness, Oxford: Oxford University Press.

—. 2008. "Virtue Ethics and the Charge of Egoism," in Bloomfield, ed. (2008, 205-21).

Birondo, Noell 2015. "Aristotle and the Virtues of Will Power," Southwest Philosophy Review 31(2): 85-94.

Bloomfield, Paul, ed. 2008. Morality and Self-Interest, New York: Oxford University Press.

Hurka, Thomas 2001. Virtue, Vice, and Value, Oxford: Oxford University Press.

Hursthouse, Rosalind 1999. On Virtue Ethics, New York: Oxford University Press.

_- Gavin Lawrence, and Warren Quinn, eds. 1995. Virtues and Reasons: Philippa Foot and Moral Theory, New York: Clarendon.

McDowell, John 1979. "Virtue and Reason," The Monist 62(3): 331-50.

—. 1980. "The Role of Eudaimonia in Aristotle's Ethics," in Rorty, ed. (1980, 359-76).

1995. "Two Sorts of Naturalism," in Hursthouse, Lawrence, and Quinn, eds. (1995, 149-79).

- 2002. "Gadamer and Davidson on Understanding and Relativism," in Malpas, Arnswald, and Kertscher, eds. (2002, 173-93).

MacIntyre, Alasdair 1984. After Virtue: A Study in Moral Theory, 2nd ed., Notre Dame: University of Notre Dame Press.

- 1999. Dependent Rational Animals, La Salle: Open Court.

—. 2002. "On Not Having the Last Word: Thoughts on Our Debts to Gadamer," in Malpas, Arnswald, and Kertscher, eds. (2002, 157-72).

Malpas, Jeff, Ulrich Arnswald, and Jens Kertscher, eds. 2002. Gadamer's Century: Essays in Honor of Hans-Georg Gadamer, Cambridge, MA: MIT Press.

Nussbaum, Martha 1995. "Aristotle on Human Nature and the Foundations of Ethics," in Altham and Harrison, eds. (1995, 86-131).

Prinz, Jesse 2009. "The Normativity Challenge: Cultural Psychology Provides the Real Threat to Virtue Ethics," Journal of Ethics 13: 117-44.

Purcell, Sebastian 2014. "Natural Goodness and the Normativity Challenge: Happiness Across Cultures," Proceedings of the American Catholic Philosophical Association 87: 183-94.

Rorty, Amélie O., ed. 1980. Essays on Aristotle's Ethics, Berkeley: University of California Press. Russell, Daniel C. 2009. Practical Intelligence and the Virtues, New York: Oxford University Press. Taylor, Charles 2002. "Understanding the Other: A Gadamerian View on Conceptual Schemes," in Malpas, Arnswald, and Kertscher, eds. (2002, 279-98). 
—. 2011. "What Does Secularism Mean?," in Dilemmas and Connections: Selected Essays, Cambridge, MA: Belknap Press, 303-25.

Toner, Christopher 2008. "Sorts of Naturalism: Requirements for a Successful Theory," Metaphilosophy 39(2): 220-50.

Williams, Bernard 1985. Ethics and the Limits of Philosophy, Cambridge, MA: Harvard University Press. 